\title{
DOCÊNCIA NA CRECHE: ENTRE SIMPLICIDADE E SOFISTICAÇÃO SUTIL
}

\author{
Rachel Arenari ${ }^{\mathrm{i}}$ \\ Patricia Corsino ${ }^{\text {ii }}$
}

\begin{abstract}
RESUMO: A expansão das creches como primeira etapa da Educação Básica impõe a intensificação de investimentos em infraestrutura e também na formação de professores e gestores que irão desenvolver o trabalho educativo junto às crianças de 0 a 3 anos. $\mathrm{O}$ que caracteriza a docência na creche? $\mathrm{O}$ que as pesquisas brasileiras têm pensando sobre as características desta docência? Nosso objetivo neste texto é pensar questões que interpelam a docência na creche. A partir de uma revisão bibliográfica de pesquisas brasileiras que fazem referências a características da docência na creche, chega a duas categorias ambivalentes: simplicidade e sofisticação sutil. As análises evidenciam que tais características levam necessariamente a assunção de uma pedagogia das relações e da participação. Mais que uma opção metodológica, este paradigma educacional é central para a significação e para o reconhecimento da docência na creche. Para fundamentar o argumento, o texto dialoga com os estudos de Oliveira-Formosinho, Falk e Bondioli.
\end{abstract}

Palavras-chave: docência; creche; formação de professores de Educação Infantil.

\section{NURSERY TEACHING: BETWEEN SIMPLICITY AND SUBTLE SOPHISTICATION}

ABSTRACT: The expansion of daycare centers as the first stage of Basic Education requires the intensification of investments in infrastructure and also in the teachers and managers education, who will develop educational work with children of 0 to 3 years old. What characterizes teaching in daycare? What have Brazilian researches thinking about the characteristics of this teaching? The aim of this article to think about issues that challenge teaching in daycare. From a bibliographic review of Brazilian researches that make reference to the characteristics of teaching at the daycare center, it reaches two ambivalent categories: simplicity and subtle sophistication. The analyzes show that such characteristics necessarily lead to the assumption of a pedagogy of relations and participation. More than a methodological option, this educational paradigm is central to the meaning and recognition of daycare teaching. To support the argument, the text dialogues with the studies of Oliveira-Formosinho, Falk and Bondioli.

Keywords: teaching; daycare; Early Chidhood Education teacher education

2020 Bargas; Ayoub; Assaritti, Scarazzatto, Assis. Este é um artigo de acesso aberto distribuído sob os termos da Licença Creative Commons Atribuição Não ComercialCompartilha Igual (CC BY-NC-4.0), que permite uso, distribuição e reprodução para fins não comerciais, com a citação dos autores e da fonte original e sob a mesma licença 
Qual é o animal mais feroz?

Perguntaram à mamãe.

É o tigre?

Não, não, não, não

O tubarão?

Não, não, não, não.

A cobra?

Não, não, não, não.

O jacaré?

Não, não, não, não.

Então, qual é?

A galinha!

Disse a mamãe minhoca

para suas filhas minhoquinhas.

(DIPACHO, 2016)

Iniciamos este artigo com o texto do livro ilustrado "O animal mais feroz", de Dipacho (2016). Uma obra de literatura infantil que se apresenta em um projeto gráfico-editorial com características que supõem como leitores crianças bem pequenas: formato quadrado, folha cartonada resistente, pouco texto, ilustrações de traços simples e cores fortes, entre outras. O livro ilustrado é um gênero que combina palavras e imagens em igual hierarquia. Suas ilustrações fazem um jogo entre a parte e o todo do corpo dos animais e o texto verbal. Cada pergunta vem em páginas duplas com a ilustração de uma parte do corpo do animal o qual a pergunta se refere, ampliada. A resposta "Não, não, não, não" vem no meio de outras páginas duplas com o animal de corpo inteiro em seu habitat. A história termina com a ilustração de um pintinho comendo uma minhoca. Este final surpreendente, diverte e nos faz refletir sobre pontos de vista: de que lugar falamos? De onde olhamos o outro? Como descentrar do eu e ir ao encontro do outro? Como sair do conhecido para acolher o novo, o inusitado, o inaugural? É com um texto verbal simples em estreita relação com imagens bem elaboradas, mas singelas, que o autor apresenta a complexidade das relações eu-outro. Esta ambiguidade nos faz indagar: por que um livro destes para bebês e crianças pequenas? O que eles podem entender do que foi lido? Como ler este livro com as crianças? O que perguntar depois da leitura partilhada?

Trazemos esta obra como alegoria, no sentido de Walter Benjamin (1992), como possibilidade de uma imagem, que apresenta algo particular, suscitar novos sentidos a serem desvelados e interpretados. Imagem dialética pelo desvio, pela interrupção do curso linear do que evoca, interrupção do obvio, do previsível e do próprio tempo linear "saturado de agoras". 
Alegoria das relações adulto- bebês-crianças no espaço público coletivo e educativo de creches, ou melhor, da docência na creche, tema que o artigo se propõe a abordar.

O objetivo deste texto é discutir questões que interpelam a docência na creche e, consequentemente, a formação de professores para atuar com crianças de 0 a 3 anos. Inicialmente, com Benjamin (1993), apresenta a história "O animal mais feroz", de Dipacho (2016) como alegoria e os números da cobertura do atendimento em creches no Brasil são abordados para justificar a relevância do tema. Numa segunda parte, traz uma revisão bibliográfica de pesquisas que fazem referências a características da docência na creche. Com este levantamento, foi organizada uma constelação, ou seja, um desenho no qual cada característica particular ganha maior significação na relação com as demais, produzindo uma totalidade, ainda que - como um lampejo -, provisória e contingente. Constelações, no entendimento de Benjamin, são como um caleidoscópio, a cada arranjo mudam o desenho e podem ganhar novas significações. A partir das pesquisas levantadas se evidencia como características da docência na creche a ambivalência entre simplicidade e complexidade sutil que levam necessariamente a assunção de uma pedagogia das relações e da participação. Na terceira parte, aborda pontos desta pedagogia em diálogo com Oliveira-Formosinho, Falk, Bondioli. Portanto, é a partir de uma imagem provisória fixada sobre a docência na creche que conclui com alguns princípios para a formação docente.

\section{PENSAR O DESVIO}

Por que tomamos a imagem particular de uma obra literária infantil como alegoria para trazer questões que interpelam a docência na creche? Porque a literatura, por ser aberta, deixa brechas e possibilita os desvios e também porque este livro é um dos que aposta nas crianças pequenas, que mantém uma relação dialógica entre forma e conteúdo. Embora seja um livro que se dá a ler como uma obra muito simples, podemos observar uma elaboração na relação texto e imagem e na maneira de tratar o tema: provocativa, instigante, convidativa. O simples não significa simplificação. O leitor presumido é chamado a participar, a pensar, a estabelecer relações, seja na observação parte-todo e todo-parte, seja na interlocução com o texto verbal, geralmente lido por um leitor mais experiente.

Revista Interinstitucional Artes de Educar. Rio de Janeiro, V. 6, N.2-pág. 489-511 maio-agosto de 2020: "Bebês e crianças: cultura, linguagem e políticas"

DOI: 10.12957/riae.2020.46700 
No início da história alguém, que não está totalmente explicito nas ilustrações, pergunta à mãe: qual é o animal mais feroz? O tigre não é, o jacaré também não é, o tubarão idem, então quem é? Quando a mamãe responde: a galinha, gera um espanto. Será? Mas, quem pergunta são as minhocas e a justificativa desta ferocidade é colocada na imagem de um pintinho com a minhoca pendurada no bico.

A obra apresenta uma simplicidade elaborada e sutil, que não subestima a criança, que aposta nos seus movimentos, percepções, respostas. Extrapola a ideia de faixa etária fechada, podendo instigar leitores variados. Assim, perguntamos: a docência na creche pode se instituir neste espaço ambivalente de simplicidade e sofisticação sutil? Pode caminhar entre apostas criativas, surpreendentes, disparadoras de dúvidas e de interlocução? Pode estabelecer entre adultos e crianças uma relação de confiança, implicada, dialógica, presente e também aberta à escuta do diverso e imprevisível?

Há mais de vinte anos, a LDB de 1996 instituiu a creche como parte da Educação Infantil, primeira etapa da Educação Básica, dedicada à educação das crianças de 0 a 3 anos. Uma faixa etária que inclui bebês e crianças pequenas que exigem muito dos adultos que os educam e cuidam. Os bebês são os recém-chegados que até bem pouco tempo eram de responsabilidade quase que exclusiva da mãe. Cuidá-los e educa-los era tarefa aprendida com e nas relações familiares, culturais e de âmbito doméstico. A creche passa a se configurar, sobretudo, como um direito das crianças a serem cuidadas e educadas também no âmbito institucional, no convívio coletivo com outras crianças. A função educativa da creche tem ganhado relevo nas pesquisas educacionais e as questões que envolvem a docência na creche têm sido consideradas relevantes para se pensar a formação de professores, como veremos mais à frente.

A Meta 1 do Plano Nacional de Educação 2014-2024, de ter 50\% das crianças brasileiras de 0 a 3 anos nas creches, induz a uma significativa expansão que exige ser atendida dentro de parâmetros de qualidade. De acordo com as informações publicadas em 2018 pelo IBGE (Instituto Brasileiro de Geografia e Estatística) entre 2016 e 2017 houve um crescimento de 2,3\% na taxa de frequência bruta nas Creches no país. Os índices de 2018 contabilizam 32,7\% das crianças na faixa etária de até 3 anos de idade que recebem este atendimento escolar, e indicam uma demanda de ampliação ainda de 17,3\% até 2024 para se chegar aos 50\% 


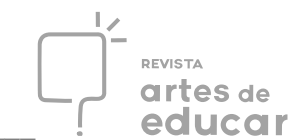

estipulados no PNE. Calcula-se que a população atual de crianças com idade de até $4 \operatorname{anos}^{1}$ seja de 14 milhões e 700 mil brasileiros em números estimados, o que nos induz a concluir que hoje as creches recebem em torno de 4 milhões e 800 mil bebês e crianças pequenas. Há, portanto, ainda um déficit a ser resolvido de 2 milhões e 500 mil vagas em creches para que se promova o atendimento de $50 \%$ da população de 0 a 3 anos e se cumpra a meta do PNE.

Para além da questão quantitativa, importa-nos pensar sobre a qualidade do atendimento nas creches brasileiras, ou seja, faz-se necessário discutir a articulação entre políticas e práticas, a docência na creche e suas peculiaridades como fator estruturante da proposta educacional com bebês e crianças pequenas no âmbito escolar. A expansão do atendimento em creches impõe a intensificação de investimentos em infraestrutura e também na formação de professores e gestores que irão desenvolver o trabalho educativo junto às crianças. Partimos das indagações: o que caracteriza a docência na creche? $\mathrm{O}$ que as pesquisas brasileiras têm pensando sobre as características desta docência? Nosso objetivo neste texto é pensar questões que interpelam a docência na creche a partir da produção científica brasileira sobre este tema. No item a seguir, traçamos uma constelação de ideias tecidas pelas e nas pesquisas desenvolvidas no Brasil entre 1996 e 2016.

\section{CONSTRUINDO A CONSTELAÇÃO}

Para mapear a produção acadêmica que aborda o trabalho docente com os bebês e crianças pequenas na creche, realizamos uma revisão bibliográfica centrada entre os anos de 1996 e 2016 de modo a abranger vinte anos após a promulgação da LDB. Os trabalhos encontrados tiveram seus resumos analisados e foram agrupados por aproximação temática.

Analisamos três bases de dados, a saber: o Banco de Dados de Teses e Dissertações plataforma do Instituto Brasileiro de Informação em Ciência e Tecnologia - BDTD/IBICT BDTD/IBICT, o banco de teses e dissertações da CAPES e os trabalhos apresentados no Grupo de Trabalho Educação da criança de 0 a 6 anos (GT07) das reuniões científicas nacionais da ANPEd - Associação Nacional de Pós-Graduação e Pesquisa em Educação, no período de 1996 a 2016, utilizando os seguintes descritores: educação infantil, creche, docência, bebê, professor e docente; alternando as combinações entre eles.

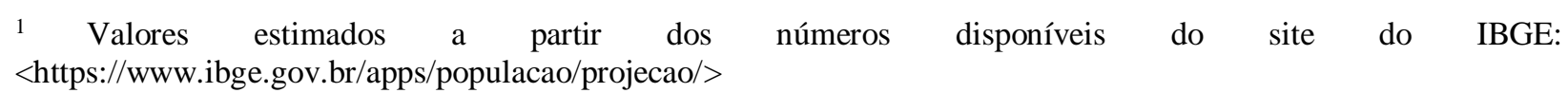

Revista Interinstitucional Artes de Educar. Rio de Janeiro, V. 6, N.2- pág. 489-511 maio-agosto de 2020: "Bebês e crianças: cultura, linguagem e políticas"

DOI: 10.12957/riae.2020.46700 


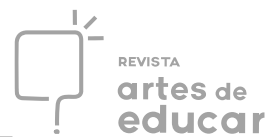

Inicialmente fizemos uma busca no BDTD/IBICT. Na primeira procura encontramos no período investigado, 21 trabalhos entre teses e dissertações que abrangiam o tema. Em um segundo momento, acrescentamos aos descritores os termos: bebê, professor e docente e foi possível encontrar mais 7 estudos nesta plataforma, totalizando 28 teses e dissertações.

No Banco de Teses e Dissertações da plataforma CAPES, utilizando os mesmos descritores e o mesmo recorte temporal, foram identificados 29 trabalhos, no entanto, dentre eles, 12 já tinham sido encontrados no BDTD/IBICT e os outros 17 estudos apareceram somente nesse banco de dados, o que significa um total de 45 trabalhos nos dois repositórios virtuais que abarcam a docência na creche direta ou indiretamente.

Em ambas as buscas identificamos poucos trabalhos apresentados sobre a temática na primeira década pós-LDB (até o ano 2006) e uma concentração maior de publicações envolvendo a docência na creche a partir do ano de 2011.

Na plataforma BDTD/IBICT, na primeira década pós-LDB/96 só foram encontradas três produções (duas dissertações e uma tese) que versavam sobre a Creche, e dentre elas apenas Tristão (2004) se debruçava especificamente sobre a docência com os bebês. As demais, Brandão (2007) e Búfalo (2009) abordam respectivamente os discursos das professoras e das famílias usuárias da Creche e a construção do profissional docente a partir do movimento sindical de Campinas. Tristão (2004, p.5) destaca como a docência com as crianças pequenas é marcada pela "sutileza das ações cotidianas, que muitas vezes não são percebidas dentro da rotina diária, mas que são determinantes na caracterização dessa profissão devido ao seu cunho humanizante". A pesquisa traz para a discussão a questão do cuidado e da educação como componentes do trabalho do professor com a fase inicial da infância.

A plataforma do BDTD/IBICT, de 2006 a 2016 , evidencia uma produção mais intensa de pesquisas envolvendo a Creche: vinte e seis trabalhos. Destes, doze abordam a questão da identidade docente e sua representação social. Há também seis pesquisas que se debruçam sobre as questões da formação e dos saberes docentes para o professor da Creche, bem como um trabalho sobre a inserção profissional do professor de bebês e crianças pequenas feito por Jacques (2014). Outros estudos se dedicam às questões relativas à especificidade docente na Creche e/ou às práticas pedagógicas como Rodrigues (2016), Vieira (2016), Winterhalter (2015), Gonçalves (2014), Schmitt (2014) e Duarte (2011).

Dentre estes trabalhos, destacamos Duarte (2011) ao identificar que a dimensão educativa da docência na Creche é marcada por relações que seriam o centro do trabalho do professor com 


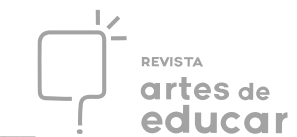

as crianças pequenas. A autora organiza a sua observação em duas categorias relacionais que se entrelaçam - as relações de cuidado e as relações corporais - e as define como dimensões educativas que consolidam esta especificidade da docência com os bebês.

Partindo também da perspectiva de que a docência se constitui na relação com os outros, Schmitt (2014, p.11) amplia o foco relacional ao afirmar que "toda e qualquer relação social vivida no âmbito da instituição (e mesmo fora desta) incide sobre a constituição das crianças e sua aprendizagem". A tese evidencia as múltiplas e simultâneas relações que se estabelecem entre os sujeitos na Creche (adultos e crianças) e indica a necessidade de pensar em uma ação docente que se efetiva não apenas pela presença diretiva das professoras, mas enfaticamente, por uma composição de tempos e espaços, que são estruturados inicialmente pelas profissionais, para as experiências pessoais e coletiva das crianças

$\mathrm{Na}$ sua dissertação, Gonçalves (2014) apresenta uma análise da produção científica brasileira entre 2008 e 2011 e busca aprofundar os estudos sobre as práticas pedagógicas com os bebês e crianças pequenas na creche. A autora utiliza como referencial teórico autoras do campo da Educação Infantil como Tristão (2006) já aqui apontada; Guimarães (2008) e sua discussão sobre o cuidado como ética, que coloca o cuidado como uma importante face da relação entre adultos e bebês na creche, e destaca a relevância dos adultos experimentarem um cuidado de si que implica o cuidado com o outro atento e disponível; Schmitt (2008) que aborda o estabelecimento de múltiplas relações entre os bebês na creche, entre si e com os adultos e demais crianças "atravessados pelas condições materiais e significações do espaço"; Coutinho (2010) e a investigação sobre a estruturação da ação social dos bebês na creche, com ações que determinam a ação dos outros e modificam sua própria ação; e Barbosa (2010) cujo texto trata das especificidades da ação pedagógica com bebês na creche. Nas categorias de análise identificadas pela pesquisadora, dentre outros aspectos, destaca-se novamente como a docência com as crianças de 0 a 3 anos aparece marcada pelas relações e pelo compartilhamento de experiências. Além disso, como resultado da pesquisa emerge a questão da organização dos tempos e dos espaços como dois elementos centrais que caracterizam a especificidade docente com essa faixa etária.

Em relação à busca na plataforma CAPES, dentre os trabalhos que ainda não tinham sido analisados na primeira busca, encontramos um trabalho que aborda as relações do gênero e o trabalho docente na Creche, dois que discutem questões de identidade profissional, seis que investigam perspectivas da formação e saberes docentes, e oito que focalizam em especial as

Revista Interinstitucional Artes de Educar. Rio de Janeiro, V. 6, N.2- pág. 489-511 maio-agosto de 2020: "Bebês e crianças: cultura, linguagem e politicas" 


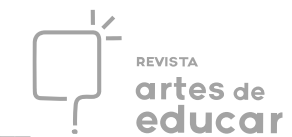

práticas docentes na Creche e as especificidades deste trabalho. Destacam-se para este estudo os trabalhos que pesquisam a formação docente para o professor da creche e os saberes que envolvem este ofício, considerando as especificidades relacionais, demandas corporais que esta etapa da educação exige, assim como as possibilidades de práticas que envolvem a linguagem com os bebês e crianças pequenas.

Em meio aos trabalhos, reencontramos referências a Tristão (2004), Guimarães (2008), Coutinho (2010), Schmitt (2014), bem como a Duarte (2011) e Fochi (2013). Na dissertação de mestrado, Demetrio (2016) aborda a questão corporal na relação educativa com os bebês na perspectiva dos professores e se baseia também, como os autores supracitados, nos estudos de Henri Wallon, Mikhail Bakhtin e Lev Vigostski. Outros dois trabalhos - Santos (2014) e Delmondes (2015) - olham para a criança a partir da perspectiva do professor da creche e concluem que ainda vigora entre os docentes uma concepção idealizada de criança, assim como na escola em que pesquisaram a prática pedagógica na creche ainda se mostra bastante diretiva com poucas oportunidades de ação livre por parte das crianças. Há ainda um estudo de Marchi (2015) de abordagem fenomenológica sobre a ação de rabiscar e desenhar com crianças de 2 a 3 anos na creche com o intuito de destacar a importância dos primeiros traços no processo de aprender a narrar na creche.

Chama também a atenção que dois, dos oito trabalhos que abordam práticas docentes, tratam do encontro da literatura com as crianças na Creche e das possibilidades da ação docente neste contexto. Escouto (2013) e Silva (2016) abordam a questão sob a perspectiva da formação do leitor literário e Salutto (2013) a partir da ideia de práticas da leitura literária com os bebês enquanto caminhos dialógicos que compõem elos de coletividade. Além do tema e de alguns autores do campo da literatura e leitura literária, os três trabalhos têm em comum o fato de se basearem nos estudos de Mikhail Bakhtin e Lev Vigotski para a discussão acerca da linguagem, além de Walter Benjamim que também foi utilizado por Salutto (2013).

Quanto aos trabalhos apresentados no GT 07 da Anped, no mesmo período e usando os mesmos descritores, primeiro fizemos tentativas por meio da ferramenta de busca da biblioteca digital disponível do site. Contudo, por esse caminho, apenas 14 trabalhos foram identificados. Optamos, então, por verificar todas as listas de trabalho apresentados no GT07 e disponíveis no site da Associação desde o ano de 1996 e encontramos um total de 36 trabalhos.

Nessa base de dados observamos um desenho de estudos similar ao que foi encontrado nas outras bases, ou seja, há uma concentração maior de trabalhos científicos que abarcam a 
convergência dos descritores utilizados a partir do ano de 2006. Considerando que nos anos anteriores havia em média menos de um trabalho por ano e que neste GT os primeiros trabalhos encontrados datam do ano de 2001. Os primeiros registros de trabalhos sobre o tema foram de Oliveira (2001) e Batista (2001). Entre os anos de 2002 e 2005 há mais três publicações, e somente em 2006 o volume de estudos apresentados começa a aumentar passando para 4 trabalhos. Com alguma oscilação dali em diante, como se pode observar no Gráfico 1, na edição de 2015 encontramos um total de 6 trabalhos apresentados.

\section{Gráfico 1- Número de produções acadêmicas consultadas nos bancos da Anped, BTD/Capes e BDTD/IBICT. Brasil -2001-2016}

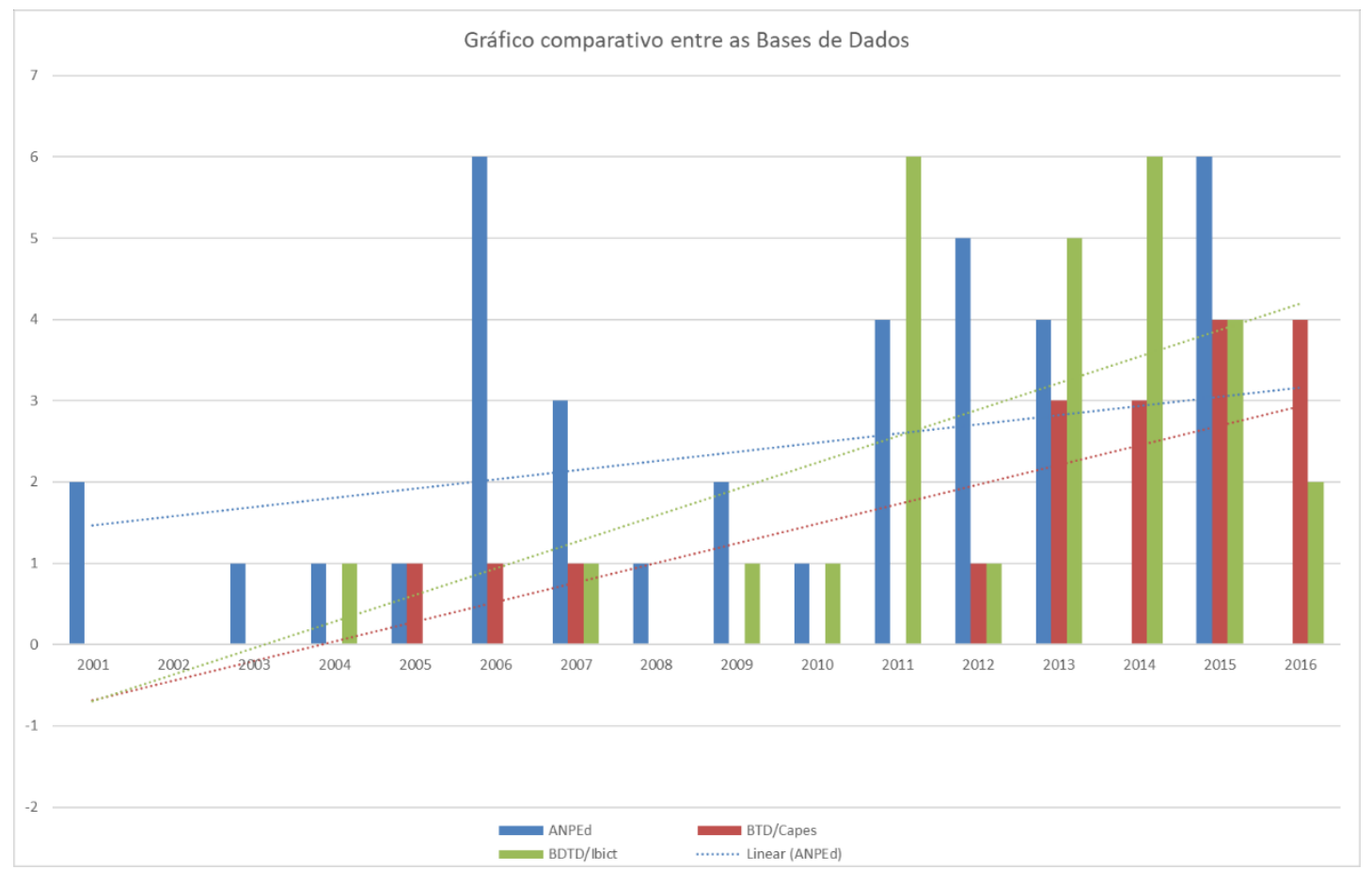

Fonte: construção da pesquisa a partir dos dados da Anped, BTD/Capes e BDTD/IBICT

O Gráfico1 evidencia um crescente interesse nas produções científicas por essa etapa educacional a partir de 2010. Observamos que há não só um aumento na produção da área como também uma diversidade de temas abordados. Não é nosso objetivo analisarmos estas produções, mas à título de referência, em linhas gerais, eles focalizam: perspectivas das políticas públicas (3), gênero (1), identidade profissional (4), formação e saberes docentes (3), história e sociologia da educação (8), especificidade do trabalho docente na creche e suas práticas (20).

Revista Interinstitucional Artes de Educar. Rio de Janeiro, V. 6, N.2- pág. 489-511 maio-agosto de 2020: "Bebês e crianças: cultura, linguagem e políticas" 
Ao considerarmos o aumento de produções acadêmicas envolvendo a docência e a Creche, podemos afirmar que há maior interesse entre os pesquisadores em debater o trabalho docente com as crianças de 0 a 3 anos. Isto se deu em virtude da constituição desta etapa educacional como um direito das crianças, um dever do estado e uma opção dos pais, das demandas legais e sociais para a ampliação deste atendimento como explicita o Plano Nacional de Educação e da consolidação de grupos de pesquisa nas universidades, especialmente as públicas, que passaram a desenvolver investigações sobre a primeira etapa da Educação Básica. Este exponencial aumento de estudos no campo nos induz a constatar como o encontro entre as crianças pequenas e os professores na Creche é perpassado por várias dimensões de ação/relação e também nos provocam a buscar ampliar o olhar para a atividade docente com as crianças pequenas.

Olhando atentamente para os resumos destacados das apresentações feitas no GT07 da ANPEd e comparando com as pesquisas igualmente encontradas nas duas outras bases de dados utilizadas neste estudo percebe-se como algumas perspectivas do trabalho docente com os bebês começam a se consolidar teoricamente. Pode-se destacar a configuração das crianças pequenas enquanto sujeitos ativos na relação com os seus pares e com o mundo, a sua potência relacional vivenciada com todo o aparato corporal ${ }^{2}$, a dinâmica do cuidado corporal e relacional enquanto um componente do trabalho pedagógico na $\mathrm{Creche}^{3}$, a compreensão de docente atenta às demandas individuais e coletivas bem como à organização do tempo e do espaço como parte integrante do trabalho pedagógico com os bebês ${ }^{4}$, sobretudo, uma docência partilhada, marcada pelas relações (DUARTE, 2011) e como afirma Gonçalves (2014) marcada pelo compartilhamento de experiências. A tese de Schmitt (2014) aponta para esta multiplicidade de relações concomitantes que se desenrolam na creche envolvendo professores, crianças, bebês, entre si e com o ambiente; indicando uma docência não-linear cercada de uma série de ações simultâneas vividas entre os atores que compõem o contexto.

Pino (2005, p.53), ao discutir sobre "Teoria genética geral do desenvolvimento cultural" de Vigotski (2009), afirma "a humanização da espécie confunde-se com o processo de produção da cultura, e a humanização do indivíduo confunde-se com o processo de apropriação dessa

\footnotetext{
${ }^{2}$ Ver SCHMITT, 2014; COUTINHO, 2010; CASTELI \& DELGADO, 2015; SALUTTO, 2013; CASTRO, 2013; dentre outros.

${ }^{3}$ Ver DEMMÉTRIO, 2016; GONÇALVES, 2014; SCMITT, 2014; DUARTE, 2011; GUIMARÃES, 2008; dentre outros.

${ }^{4}$ Ver SIMIANO \& VASQUES, 2011; GUIMARÃES, 2008; SCHMITT, 2014; GONÇALVES, 2014; dentre outros.

Revista Interinstitucional Artes de Educar. Rio de Janeiro, V. 6, N.2- pág. 489-511 maio-agosto de 2020: "Bebês e crianças: cultura, linguagem e políticas"
} 


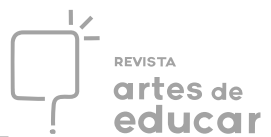

cultura”. A ação docente na creche, com os recém-chegados ao mundo, se coloca diante dessa complexa relação na qual aquilo que é da ordem da natureza e da ordem da cultura se fundem e se desdobram em ganhos culturais que se estabelecem no humano e passam a constituí-lo.

A construção desta constelação nos levou a reiterar a alegoria anunciada a partir da obra “O animal mais feroz” (DIPACHO, 2016): a ambivalência entre simplicidade e sofisticação sutil. Simplicidade no sentido de que as pesquisas apontam para um centro: a questão relacional, uma pedagogia que se funda na participação das crianças e nas relações interpessoais, uma proposta difundida há muito tempo e que não se reduz à creche. Mas, segundo as pesquisas, a perspectiva relacional na creche se daria de forma sofisticada e sutil de uma docência partilhada não linear sustentada em relações que: i) têm demandas corporais nas quais o cuidado se configura como ética; ii) são atravessadas pelas condições materiais e possibilidades de significação na composição espaço-temporal onde elas acontecem; iii) as ações do outro modificam constantemente as próprias ações numa mútua afetação entre sujeitos; iv) desencadeiam ações que são simultânea e concomitantemente vividas pelos diferentes atores que compõem o contexto educativo; v) provocam respostas constantes às demandas individuais e coletivas, respostas responsáveis, fruto de uma atenção cuidadosa; vi) se desdobram em caminhos dialógicos que compõem elos de coletividade; vii) possam se constituir enquanto experiência, ou seja, relações que alteram o sujeito, ampliam suas referências, seu conhecimento de si, do outro e do mundo; viii) têm os vínculos entre crianças e adultos como elos importantes destas relações. Entendemos que a construção de uma prática pedagógica ancorada nesta ideia de simplicidade e sofisticações sutis exige um trabalho reflexivo, com observação atenta e cuidadosa das crianças, registros do observado e das práticas vividas e partilha entre professores. Tudo isso interpela não apenas as práticas, mas também as políticas, já que são necessárias condições de produção desta práxis o que inclui investimentos diversos em infraestrutura e na formação inicial e continuada de professores como pontos chave.

As pedagogias participativas e relacionais têm sido discutidas desde o final do Séc. XIX e início do Séc. XX, como propostas para a educação de todas as faixas etárias. Mas como as pesquisas apontaram, para o exercício da docência com crianças de 0 a 3 , são propostas relacionais que vão conferir à creche o lugar educativo. Portanto, mais que uma opção metodológica, trata-se da assunção de um paradigma educacional que é central para a significação e para o reconhecimento da docência na creche. Reiteramos o que as pesquisas apontam: ser docente na creche significa abraçar o paradigma participativo e relacional, ou seja, 


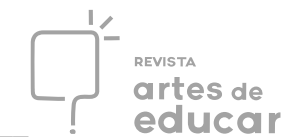

desconstruir a ideia transmissiva e instrucional que predominam a docência nas outras etapas educacionais. Este paradigma inclui necessariamente sensibilidade e disponibilidade para acolher o que vem das crianças, entendidas como sujeitos potentes que, nas interações que estabelecem, criam e transformam. Trazemos a seguir questões que dizem respeito à especificidade destas pedagogias para a primeira infância.

\section{DOCÊNCIA NA CRECHE: ALGUMAS CONSIDERAÇÕES SOBRE PERSPECTIVAS RELACIONAIS E PARTICIPATIVAS}

A partir dos apontamentos feitos sobre as especificidades da docência com os bebês e crianças pequenas que surgem no campo da pesquisa educacional e diante do nosso interesse em discutir questões que interpelam a docência na creche, recorremos a Oliveira-Formosinho (2007a; 2007b) para compreender o termo cunhado pela autora de práxis de participação. A autora explica este conceito quando se propõe a resgatar o pensamento de pedagogos dos séculos XIX e $\mathrm{XX}^{5}$ que instauraram, cada um a seu modo, pedagogias que romperam com a lógica da transmissão para se pautarem na lógica da participação. Isso porque ela entende que estas pedagogias carregam a sabedoria que necessitamos para desenvolver uma "pedagogia transformativa, que credita a criança com direitos, compreende a sua competência, escuta a sua voz para transformar a ação pedagógica em uma atividade compartilhada" (2007b. p.14).

Vale destacar o conceito de práxis tomado da teoria marxista que Konder (1992) apresenta como sendo

[...] a atividade concreta pela qual os sujeitos humanos se afirmam no mundo, modificando a realidade objetiva e, para poderem alterá-la, transformando-se a si mesmos. É a ação que, para se aprofundar de maneira mais consequente, precisa da reflexão, do autoquestionamento, da teoria; e é a teoria que remete à ação, que enfrenta o desafio de verificar seus acertos e desacertos, cotejando-os com a prática (KONDER, 1992, p. 115).

Conceito que traz este movimento da ação que se aprofunda na e pela reflexão teórica e de uma teoria que se põe à prova ao se cotejar com a prática. Conceito utilizado por Paulo Freire em suas diferentes obras ao entender a educação como um ato político, ético e estético e ao

\footnotetext{
${ }^{5}$ Sendo eles: Froebel, Dewey, Montessori, Freinet, Piaget, Vigotski, Bruner e Malaguzzi (OLIVEIRAFORMOSINHO, 2007b).
}

Revista Interinstitucional Artes de Educar. Rio de Janeiro, V. 6, N.2- pág. 489-511 maio-agosto de 2020: "Bebês e crianças: cultura, linguagem e políticas" 


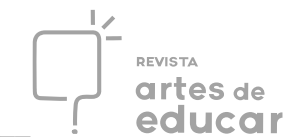

discutir a educação como prática de liberdade e emancipação, cujo ponto de partida para a reflexão é a situação concreta, a realidade, o meio existencial, e cujo método é o diálogo entre sujeitos. A práxis educativa freiriana é reflexão e ação dos homens sobre o mundo para transformá-lo e ao fazê-lo transforma-se a si mesmo. Conceito que apresenta a participação como princípio e que está no cerne da discussão de Oliveira-Formosinho (2007 b) ao discutir as pedagogias voltadas para a primeira infância. A autora ao considerar a práxis como o lócus da Pedagogia, ou seja, o lugar onde a Pedagogia se realiza, defende que ela se organize "em torno dos saberes que se constroem na ação situada em articulação com as concepções teóricas e com as crenças e valores” (p.14). A práxis emerge da triangulação entre estas crenças e valores, saberes e teorias, e ações práticas, de modo que há uma permanente relação entre a intencionalidade do ato educativo e o seu prosseguimento com os sujeitos envolvidos no contexto educacional. Concordamos com Fochi (2013) quando acentua que, ao agregar os valores e crenças ao binômio teoria e prática, Oliveira-Formosinho situa uma dimensão importante do seu conceito de práxis: seja por causar uma dinamicidade ao conhecimento pedagógico - sendo a cultura este elemento dinamizador-, seja por assentar a produção do conhecimento em um contexto histórico e cultural. Neste caminho, a práxis não acontece como uma ação docente estanque ou isolada do contexto sócio-cultural das crianças e dos professores, mas justamente se promove na complexidade da relação dialética entre os saberes e as crenças, os saberes e as práticas, as práticas e as teorias; sem, no entanto, perder de vista a interlocução com conhecimentos, comunidade, crianças e famílias.

Como a autora anuncia, uma Pedagogia pautada na participação demanda escuta, diálogo e negociação, e aloca os sujeitos no lugar ativo e de coautoria de suas jornadas. Assim, elenca alguns verbos para identificar os objetivos educacionais na perspectiva da participação: promover, estruturar, envolver-se, construir, dar significado, atuar. E quando nos referimos à prática pedagógica estamos conferindo este entendimento de práxis, a este modo intencional e participativo de ser docente, que tem objetivos claros, porém necessariamente abertos ao imprevisível, ao surgimento de diferentes possibilidades e descobertas que conduzam a uma construção coletiva e individual de conhecimento, entrelaçados na relação professor-criança, criança-criança, professor-professor e criança-professor. Assim, a pedagogia participativa tem uma centralidade relacional que se situa nas inter-relações com os outros (adultos e crianças), com a teoria e dentro de um contexto sócio educacional e cultural.

Revista Interinstitucional Artes de Educar. Rio de Janeiro, V. 6, N.2- pág. 489-511 maio-agosto de 2020: "Bebês e crianças: cultura, linguagem e políticas" 
Franco $(2015 ; 2016)$ discute a epistemologia do conceito de prática pedagógica mais voltada para o trabalho docente com crianças maiores, mas também concebe a prática no sentido de práxis. A autora anuncia esta prática como uma ação consciente e participativa que emerge da multidimensionalidade do ato educativo. Desta forma, considera que para ser uma prática pedagógica faz-se necessário estar carregada de intencionalidade e precisa ser tecida e (re)construída a cada momento e a cada circunstância do cotidiano escolar. Segundo Franco (2015, p.603) a prática pedagógica se configura "na mediação com o outro, ou com os outros, e é esse outro que oferece às práticas seu espaço de possibilidade". Em razão disto, para serem consideradas práticas pedagógicas exige-se intencionalidade, avaliação constantes e acertos contínuos de rota. Franco $(2015 ; 2016)$ aponta ainda que, a seu ver, a prática desarticulada, avulsa, desconectada do todo pode ser considerada uma prática docente, mas carece do fundamento pedagógico para ser considerada prática pedagógica. Assim, afirma que

O professor, no exercício de sua prática docente, pode ou não se exercitar pedagogicamente. Ou seja, sua prática docente para se transformar em prática pedagógica requer, pelo menos, dois movimentos: o da reflexão crítica de sua prática e o da consciência das intencionalidades que presidem suas práticas. (FRANCO, 2015, p.605)

Falk (2016) de forma bastante taxativa reitera que

\begin{abstract}
Para a educação de crianças pequenas que não são os seus próprios filhos, não basta o senso comum, nem a espontaneidade, nem o instinto maternal, mas requer uma competência especial, um controle e supervisão continuada. [. . .] Apesar do caráter pessoal dos cuidados prestados e da dedicação, o educador tem que ser consciente de que é um profissional e ter muito claro que não está educando seu filhinho. (p.20-21)
\end{abstract}

Para que esta prática pedagógica aconteça em uma pedagogia que conceba os bebês e as crianças pequenas ativos e competentes relacional e socialmente, seguimos com OliveiraFormosinho (2007, p.19) que propõe três tarefas centrais: a) a construção de contextos educativos complexos que possibilitem a emergência de múltiplas possibilidades e construção participativa do conhecimento, b) a assunção de um modo pedagógico ancorado na relação - um espaço de interação e escuta, c) e por fim, em diálogo com a história, a escolha de uma gramática pedagógica que oportunize o pertencimento a "uma comunidade aprendente que partilhe um modo de fazer pedagogia" e contribua para a construção do conhecimento acerca daquele fazer. Estas três tarefas se articulam ao que as pesquisas produzidas no Brasil têm

Revista Interinstitucional Artes de Educar. Rio de Janeiro, V. 6, N.2- pág. 489-511 maio-agosto de 2020: "Bebês e crianças: cultura, linguagem e políticas" 
apontado como característica da docência na creche, elencamos anteriormente por nós nas dimensões da simplicidade e da sofisticação sutil. Embora tais dimensões tenham dado ênfase nas interações, reiteramos a importância da dimensão coletiva da reflexão, não só por tratar-se de uma docência partilhadas, mas como práxis que se desdobra no coletivo institucional, tendo uma importante dimensão política.

A autora apresenta também tarefas que colocam o/a professor/a em três campos de ação: o contexto educativo, a relação, e a interlocução e reflexão sobre a prática com um coletivo capaz de tecer um modo de fazer pedagógico. A questão dos contextos educativos se direciona na concepção de que a aprendizagem é situada e demanda um contexto social e pedagógico que sustente, promova e facilite a participação da criança, ou como diz a autora que "participe da construção da participação" (OLIVEIRA-FORMOSINHO, 2007, p.22). O contexto educativo abrange a pedagogicidade dos espaços e dos materiais (sua escolha, organização, disposição intencionais), mas não se resume a eles. De acordo com Bondioli o contexto (2008) constitui-se em processo no qual as dimensões materiais, relacionais e simbólicas se definem constantemente, de modo dinâmico e recíproco, desvelando e consolidando a identidade educativa da instituição.

Falk (2016) também aponta nesta direção a partir da proposta educativa com as crianças de 0 a 3 anos da abordagem Pikler ${ }^{6}$. A autora considera que o adulto provoca o desenvolvimento da criança pequena e do bebê de maneira indireta e sua atuação cria oportunidades de um desenvolvimento equilibrado no âmbito emocional, afetivo, psicomotor e cognitivo. Isto se dá por meio da riqueza do ambiente, da diversidade material, de múltiplas possibilidades de experimentação do meio, do respeito ao ritmo das aquisições motoras de cada criança, e de uma rica linguagem gestual e verbal.

Já a perspectiva relacional se coloca na participação guiada por meio da observação, da escuta e da negociação, que abrem espaço para uma ação docente que pode superar a ideia de homogeneidade educacional, e se permitir acolher a heterogeneidade e a diferença como riqueza para a aprendizagem. A especificidade educacional está, assim, muito ligada à qualidade dos relacionamentos e à confirmação do lugar da criança como sujeito social.

Bondioli e Mantovani (1998) abordam a educação com crianças de 0 a 3 anos de idade e apresentam a Pedagogia do relacionamento, as autoras esclarecem que esta abordagem se

\footnotetext{
${ }^{6}$ Criada pela pediatra húngara Emmi Pikler que atuou como diretora e pesquisadora de uma Instituição de Acolhimento em Budapeste para crianças órfãs que era chamada de Instituto Lóczy e após o seu falecimento passou a ser chamado Instituto Emmi Pikler (FALK, 2010).
}

Revista Interinstitucional Artes de Educar. Rio de Janeiro, V. 6, N.2-pág. 489-511 maio-agosto de 2020: "Bebês e crianças: cultura, linguagem e politicas" 


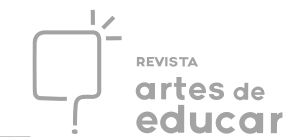

direciona à possibilidade de professores/as e crianças pequenas estabelecerem também uma relação individualizada, e que as atividades se parecem mais brincadeiras de descobertas do que lições. Corroboram com Oliveira-Formosinho na perspectiva de uma organização de tempos e espaços que favoreçam a espontaneidade das relações, onde os adultos e crianças se encontrem como coparticipantes no processo aprendizagem e interação. Tendo como base a socialização da criança, anunciam, ainda, um entrelaçamento entre o contexto e a perspectiva relacional.

Guimarães e Leite (1999), a partir do entendimento das autoras italianas, apontam que ao considerar as crianças sujeitos ativos, criativos, formuladores de hipóteses e transformações, entende-se que o professor (na nomenclatura das italianas: educador) na relação adulto-criança na creche:

[. . .] é convocado a favorecer as condições de ação das crianças; ter sensibilidade e disponibilidade; ser companheiro de brincadeiras; estabelecer cumplicidade. Assim, a ludicidade, a continuidade e diversificação das experiências garantem a produção de significados, fundamental na estruturação das aprendizagens, na relação com o mundo externo, na socialização. O adulto é um facilitador das relações e capaz de propiciar crescimento. (GUIMARÃES; LEITE, 1999, p.5)

Bondioli e Mantovani (1998) utilizam três palavras para especificar o que chamam de uma didática do fazer: ludicidade, continuidade e significatividade. De acordo com as autoras, esta didática é um convite ao fazer, explorar o mundo e seus objetos, suas cores, formas, e olhálo, tocá-lo, manipulá-lo e transformá-lo (1998, p.31). Com a ludicidade as crianças desfrutam de um clima de relativa liberdade e permite que experimentem lugares "outros", personagens, histórias, sem temores ou culpa. A continuidade das experiências dialoga com uma configuração de mundo das crianças pequenas e bebês muito situada no presente. Assim, seja por meio da rotina (que estabelece tempos e hábitos), seja na ampliação e enriquecimento das experiências vividas, é que se cria para elas a possibilidade de generalização e integração (inclusive conceitual). A questão do significado está vinculada a experiências significativas que provoquem e ofereçam possibilidades de desenvolvimento, de novas descobertas que emergem das e nas experiências já vividas.

Como também destaca Coutinho (2010, p.213):

A educação dos bebês em creche é, sem dúvidas, uma conquista das famílias, sobretudo as trabalhadoras, mas também é uma conquista dos próprios bebês, que podem gozar do direito a ter um espaço intencionalmente organizado para

Revista Interinstitucional Artes de Educar. Rio de Janeiro, V. 6, N.2- pág. 489-511 maio-agosto de 2020: "Bebês e crianças: cultura, linguagem e políticas"

DOI: 10.12957/riae.2020.46700 
recebê-los, em que o encontro com os pares é uma prerrogativa constante. A creche é então entendida, antes de mais, como um espaço de educação em que o encontro com o outro, a brincadeira, a ampliação dos repertórios linguísticos, sociais, culturais, mediante a ação social pelo corpo, pelas trocas e a descoberta são reveladoras das possibilidades encontradas nesse lugar.

Ao abordarmos o eixo da relação, destacamos que na abordagem Pikler considera-se o vínculo adulto-bebê um dos pilares da constituição do sujeito bem como um dos princípios que direcionam a prática do adulto. Falk (2016) dá destaque para os momentos de cuidados corporais nesta relação que abrange o diálogo com o corpo e as palavras, a sutileza dos movimentos e a atenção mais profunda, e é categórica ao afirmar que: “A criança não aceita os cuidados de forma passiva. Participa ativamente. $\mathrm{O}$ adulto não exige esta participação, mas a torna possível motivando-a e valorizando-a" (FALK, 2016, p.23).

Nestas perspectivas, ações, expressões gestuais ou verbais, descobertas e interesses das crianças, entrelaçados nos fios das relações interpessoais tecem também uma negociação como uma resposta que coloca bebês e crianças no lugar de coautores de suas jornadas escolares, do seu currículo. Nas palavras de Oliveira-Formosinho sobre o trabalho da Pedagogia do relacionamento "o diálogo e as trocas são elementos fundamentais na construção de uma escola que se sustenta nas interações, colaborações e comunicação" (2007b, p.103).

No que tange à afirmação de uma gramática pedagógica, a autora se refere ao fato de se escolher um modelo pedagógico que alinhe um quadro de valores, uma teoria e uma prática, ou seja, que contenha um referencial teórico para pensar a criança e seu processo educacional; bem como para constituir "um referencial prático para pensar antes-da-ação, na-ação e sobre-a-ação" (OLIVEIRA-FORMOSINHO, 2007b, p.31). Esta adoção de um modelo pedagógico pode, desavisadamente, parecer um agente limitador das práticas docentes ou da ação das crianças, e se colocar como muros que dificultam o percurso de desenvolvimento das crianças e professores em relação na creche. Entretanto, o que a autora preconiza é o acolhimento de uma gramática pedagógica que sustente a práxis da participação e possa oferecer uma base para a articulação entre o contexto e os processos de desenvolvimento de crianças e professores/as, que funcione como um referencial para a organização do coletivo e das atividades individuais e que, sobretudo, mantenha o contexto escolar aberto para a criação de experiências de aprendizagens entre professores e crianças e entre os próprios professores. Conforme Oliveira-Formosinho:

Revista Interinstitucional Artes de Educar. Rio de Janeiro, V. 6, N.2- pág. 489-511 maio-agosto de 2020: "Bebês e crianças: cultura, linguagem e políticas" 
O modelo pedagógico como janela é uma gramática que cria linguagem, significados, uma estrutura conceitual e prática, um contexto de experiência e comunicação com a experiência; um contexto de ação e reflexão-sobre-a-ação. Este modelo implica uma gramática curricular aberta à reconstrução individual e coletiva, com uma didática flexível em permanente construção. (2007b, p.3132)

Neste diálogo buscamos apontar alguns encontros conceituais da abordagem Pikler e da proposta italiana da Pedagogia dos relacionamentos com a perspectiva cunhada por OliveiraFormosinho de uma Pedagogia da participação para a infância. Estas convergências discursivas se apresentam para nós como caminhos profícuos para a sustentação de uma prática pedagógica enquanto práxis na educação com bebês e crianças pequenas na creche.

\section{CONSIDERAÇÕES FINAIS}

Retomando o ponto de partida proposto na alegoria inspirada pela obra "O animal mais feroz", de Dipacho, vimos que a docência na creche exige tanto o deslocamento de uma pedagogia transmissiva e instrucional, quanto de uma pedagogia espontaneista, já que a prática pedagógica enquanto práxis, é uma ação docente marcada pela intencionalidade e pela participação. Uma práxis associada a um entendimento pedagógico que contempla o lugar ativo das crianças nas relações, que tenha centralidade nas interlocuções e processos dialógicos situados em um contexto sócio educacional e cultural com amplas possibilidades de ação, participação e de ampliação de referências. Oliveira-Formosinho (2007a, 2007b), Falk (2016) e Bondioli e Mantovani (1998) destacam a necessidade da adoção de um modelo pedagógico que se realize como janela e não como muro, e que estabeleça um chão comum para a efetivação de uma comunidade pedagógica e aprendente para o trabalho docente com bebês e crianças pequenas na creche. Diante destas discussões nos recolocamos a perscrutar esta docência; marcadamente atravessada pelos encontros entre crianças, professores e famílias, estruturalmente partilhada e compartilhada.

A afirmação da docência na creche nesta perspectiva relacional e participativa, sendo de uma sofisticação sutil, é bastante exigente. Exige do docente sensibilidade, possibilidade de escuta e de resposta, além de estudo, reflexões individuais e coletivas, criatividade na organização de contextos provocativos, que favoreçam brincadeiras, ações e interações, uma didática do fazer cuja gramática se constitui de ludicidade, continuidade e significatividade. 


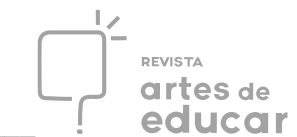

Tudo isso para se consolidar precisa fazer parte de processos formativo também participativos e relacionais. Portanto, não basta ter tempo e espaço de formação se os professores não são coparticipantes deste processo. Também não é transformadora uma formação cindida. Como assevera Bakhtin (2006), ciência, arte e vida são campos da cultura humana que tanto podem adquirir unidade no indivíduo que os incorpora, como permanecer cindidos e manter entre si apenas uma relação mecânica e externa. Por isso, partilhamos uma concepção de formação de professores que rompa com a visão de ciência e arte como autônomas, autossuficientes ou isoladas da vida para propor espaços formativos que tragam a arte, que aprofundem questões levantas por diversos campos científicos, mas que se articulem à vida de professores/as e crianças. Esta perspectiva tem como objetivo que os/as professores/as se coloquem dialogicamente disponíveis para escutar, responder, provocar, sustentar, criar e dialogar a partir de suas vivências pessoais, com colegas que partilham a docência, com as crianças e também com vozes teóricas capazes de sustentar concepções e de encontrar caminhos, com um olhar sensível e ampliado pelas possibilidades de fruição estética.

Pensar a formação docente para a atuação com crianças de 0 a 3 anos no espaço coletivo da creche é exigente porque precisa se descentrar de paradigmas transmissivos ou centrados em visões descontextualizadas. Como o livro "O animal mais feroz" nos instiga, a resposta de qual seria o animal mais feroz depende de quem pergunta. Na creche, a pedagogia exige indagar: quem são as crianças de 0 a 3 anos? Como pensamos o seu desenvolvimento e possibilidades? Onde nós, adultos, nos situamos frente às crianças? Como perguntar a partir das perguntas que bebês e crianças nos fazem? Como responder perguntas muitas vezes não verbais que exigem escuta atenta e participação intensiva na relação?

Temos defendido a didática, ou a prática pedagógica, como ato responsivo (CORSINO, 2015), um ato que exige uma resposta responsável. Na creche este ato responsivo se instaura no compromisso com a ação que a natalidade enseja: "a permanente e igualitária capacidade de começar algo novo". (ARENDT, 1997, p. 349). Um começar algo novo comprometido ética e politicamente com a ressignificação da história, com a superação do instituído que homogeneíza, silencia e oprime, com a abertura de novas possibilidades fora do que está posto.

\section{REFERÊNCIAS}

Revista Interinstitucional Artes de Educar. Rio de Janeiro, V. 6, N.2- pág. 489-511 maio-agosto de 2020: "Bebês e crianças: cultura, linguagem e politicas" 
ARENDT, H. Entre o Passado e o Futuro. Tradução de Mauro W. Barbosa de Almeida. São

Paulo: Perspectiva, 1997.

BAKHTIN, M. Estética da criação verbal. Tradução Paulo Bezerra. São Paulo: Martins Fontes, 2006.

BARBOSA, M. C. As especificidades da ação pedagógica com os bebês.

[S.I.]:2010.Disponível em:

<http://portal.mec.gov.br/index.php?option=com_docman\&view=download\&alias=6670asespecificidadesdaacaopedagogica\&Itemid=30192>. Acesso em: 26 de jan. 2017.

BATISTA, R. A rotina da creche: entre o proposto e o vivido. $24^{\text {a }}$ Reunião da ANPEd, GT 07. Caxambu, MG: 07 a 11 de outubro de 2001. Disponível em <www.anped.org.br>. Acesso em: 27 de jan. 2017.

BENJAMIN, Walter. Obras escolhidas II: Rua de mão única. São Paulo: Brasiliense 1993.

BONDIOLI, A.; MANTOVANI, S. Manual de educação infantil: de 0 a 3 anos - uma abordagem reflexiva. Porto Alegre: Artmed, 1998.

BRANDÃO, S. M. B. de A. A centralidade da maternagem na relação pedagógica da educação infantil: o discurso de docentes e famílias usuárias de creche. Dissertação de Mestrado. Mestrado Interdisciplinar em Ciências da Sociedade - EUPB - Campina Grande, 2007.

BRASIL. Lei no 9.394 de 20 de dezembro de 1996. Estabelece as diretrizes e bases da educação nacional. Disponível em: <http://www.planalto.gov.br/ccivil_03/leis/L9394.htm>. Acesso em: 01 de jan. 2017.

Ministério da Educação. Secretaria de Articulação com os Sistemas de Ensino.

Planejando a Próxima Década - Conhecendo as 20 Metas do Plano Nacional de Educação. Brasília: MEC, SASE, 2014. Disponível em: <http://pne.mec.gov.br/ images/pdf/pneconhecendo_20_metas.pdf>. Acesso em: 08 de mai. 2017.

BÚFALO, J. Nem só de salário vivem as docentes de creche: em foco as lutas do Sindicato dos Trabalhadores no Serviço Público Municipal de Campinas. Tese de Doutorado. Faculdade de Educação - UNICAMP - Campinas, 2009.

CASTELLI, C. M.; DELGADO, A. C. C. Bebês que se relacionam com crianças mais velhas: cuidados e conflitos na educação infantil. $37^{\mathrm{a}}$ Reunião da ANPEd, GT 07. Florianópolis, SC: 4 a 8 de outubro de 2015. Disponível em <www.anped.org.br>. Acesso em: 05 de fev. 2016.

CASTRO, J. S. de. Constituição da linguagem entre os e dos bebês no espaço coletivo da

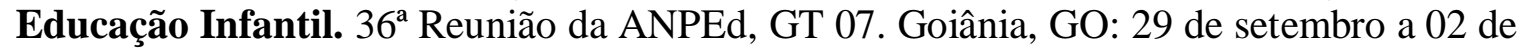
outubro de 2013. Disponível em <www.anped.org.br>. Acesso em: 26 de jan. 2017.

Revista Interinstitucional Artes de Educar. Rio de Janeiro, V. 6, N.2- pág. 489-511 maio-agosto de 2020: "Bebês e crianças: cultura, linguagem e políticas" 
CORSINO, P. A didática como ato responsivo. Educação \& Realidade, Porto Alegre, v. 40, n. 2, p. 399-419, abr./jun. 2015.

COUTINHO, Â. Ação social dos bebês: um estudo etnográfico no contexto da creche. Tese de Doutorado. Instituto de Educação - UNIVERSIDADE DO MINHO - Minho, 2010.

DELMONDES, I. S. dos S. A educação da criança de 0 a 3 anos - um olhar para a prática docente. Dissertação de Mestrado. Programa de Pós-Graduação em Educação - UCDB - Campo Grande, 2015.

DEMMÉTRIO, R. V. A dimensão corporal na relação educativa com bebês: na perspectiva das professoras. Dissertação de Mestrado. Programa de Pós-Graduação em Educação - UFSC Florianópolis, 2016.

DIPACHO. O animal mais feroz. São Paulo: V\&R Editoras, 2016.

DUARTE, F. Professoras de bebês: as dimensões educativas que constituem a especificidade da ação docente. Dissertação de Mestrado. Programa de Pós-Graduação em Educação - UFSC - Florianópolis, 2011.

ESCOUTO. N. de B. A formação do leitor - literário na educação infantil: a interação da palavra da vida cotidiana com a palavra literária. Dissertação de Mestrado. Programa de PósGraduação em Educação - UFSC - Florianópolis, 2013.

FALK, J. (Org.) Abordagem Pikler Educação Infantil. São Paulo: Omnisciência, 2016.

FOCHI, P. S. Mas os bebês fazem o quê no berçário, heim? Dissertação de Mestrado. Programa de Pós-Graduação em Educação - UFRGS - Porto Alegre, 2013.

FRANCO, M. A. S. Práticas pedagógicas de ensinar-aprender: por entre resistências e resignações. Revista Educ. Pesqui., v. 41, n. 3, p.601-614, jul/set. 2015.

FRANCO, M. A. S. Prática pedagógica e docência: um olhar a partir da epistemologia do conceito. Revista Brasileira de Estudos Pedagógicos, v. 97, n. 247, p.534-551, set/dez. 2016.

GONÇALVES, F. A educação de bebês e crianças pequenas no contexto da creche: uma análise da produção científica recente. Dissertação de Mestrado. Programa de Pós-Graduação em Educação - UFSC - Florianópolis, 2014.

GUIMARÃES, D. de O. Entre a instrução e o diálogo: a construção da identidade educacional das creches. 2006. Disponível em:

<http://29reuniao.anped.org.br/trabalhos/trabalho/GT07-2328--Int.pdf>. Acesso em: $01 \mathrm{de}$ dez. 2015.

GUIMARÃES, D. de O. Relações entre Crianças e Adultos no Berçário de uma Creche Pública na Cidade do Rio de Janeiro: técnicas corporais, responsividade, cuidado. Tese de Doutoramento. Programa de Pós-Graduação em Educação - PUC-Rio - Rio de Janeiro, 2008.

Revista Interinstitucional Artes de Educar. Rio de Janeiro, V. 6, N.2- pág. 489-511 maio-agosto de 2020: "Bebês e crianças: cultura, linguagem e politicas" 
GUIMARÃES, D. de O.; LEITE, M. I. A pedagogia dos pequenos: uma contribuição dos autores italianos. 22 ${ }^{\mathrm{a}}$ Reunião anual da ANPED, Caxambu, Set/1999. Disponível em: <www.anped.org.br>. Acesso em 15 mar. 2017.

JACQUES, R. E. H. Inserção na creche e relações sociais. Dissertação de Mestrado. Programa de Pós-Graduação em Educação - UFCS - Florianópolis, 2014.

IBGE - Instituto Brasileiro de Geografia e Estatística. Projeções e estimativas da população do Brasil e das Unidades da Federação. Disponível em:

<https://www.ibge.gov.br/apps/populacao/projecao/>. Acesso em 06 set. de 2019.

IBGE. Síntese de Indicadores Sociais - SIS. Disponível em:

$<$ https://www.ibge.gov.br/estatisticas/sociais/educacao/9221-sintese-de-indicadoressociais.html?=\&t=resultados $>$. Acesso em 06 set. de 2019.

KONDER, L. O futuro da filosofia da práxis: o pensamento de Marx no século XXI. Rio de Janeiro: Paz e Terra, 1992.

MARCHI, R. M. Rabiscar e aprender a narrar desenhando na creche. Dissertação de Mestrado, Programa de Pós-Graduação em educação, Universidade de Santa Cruz do Sul UNISC. Santa Cruz do Sul-RS, 2015.

OLIVEIRA, A. M. R. de. Com Olhos De Criança: o que elas falam, sentem e desenham sobre sua infância na creche. $24^{\mathrm{a}}$ Reunião da ANPEd, GT 07. Caxambu, MG: 07 a 11 de outubro de 2001. Disponível em <www.anped.org.br>. Acesso em: 26 de jan. 2017.

OLIVEIRA-FORMOSINHO, J. Pedagogia(s) da infância: reconstruindo uma práxis de participação. In: OLIVEIRA-FORMOSINHO, J.; LINO, D.; NIZA, S. Modelos Curriculares para a Educação de Infância - construindo uma práxis de participação. Porto: Porto Editora, 2007a.

OLIVEIRA-FORMOSINHO, J. Pedagogia(s) da infância: reconstruindo uma práxis de participação. In: OLIVEIRA-FORMOSINHO, J.; KISHIMOTO, T. M.; PINAZZA, M. A. Pedagogia(s) da Infância: dialogando com o passado, construindo o futuro. Porto Alegre: Artmed, 2007b.

PINO, A. As marcas do humano: às origens da constituição cultural da criança na perspectiva de Lev S. Vigotski. São Paulo: Cortez, 2005.

ROCHA, M. R. de S. Perspectivas de uma educação dialógica na creche: a co-autoria da criança na construção da prática educativa. Dissertação de Mestrado. Programa de PósGraduação em Educação - UNIRIO - Rio de Janeiro, 2012.

RODRIGUES, S. Viajando pela educação da primeiríssima infância: sentidos, crenças e valores que sustentam os saberes e as práticas pedagógicas na/da creche. Tese de Doutorado. UNESP - São Paulo, 2016.

Revista Interinstitucional Artes de Educar. Rio de Janeiro, V. 6, N.2- pág. 489-511 maio-agosto de 2020: "Bebês e crianças: cultura, linguagem e políticas" 
SALUTTO, M. N. de S. de M. Leitura literária na creche: o livro entre texto, imagens, olhares, corpo e voz. Dissertação de Mestrado. Programa de Pós-Graduação em Educação UFRJ - Rio de Janeiro, 2013.

SANTOS, C. G. L. dos. As relações pedagógicas e sociais no contexto da educação infantil: o papel/lugar da criança na perspectiva do professor. Dissertação de Mestrado. Programa de Pós-Graduação em Educação - UCDB - Campo Grande, 2014.

SCHMITT, R. V. "Mas eu não falo a língua deles"! As relações sociais de bebês num contexto de Educação Infantil. Dissertação de Mestrado. Programa de Pós-Graduação em Educação - UFSC - Florianópolis, 2008.

SCHMITT, R. V. As relações sociais entre professoras, bebês e crianças pequenas: contornos da ação docente. Tese de Doutorado. Programa de Pós-Graduação em Educação UFSC - Florianópolis, 2014.

SILVA, M. M. Formação do Leitor Literário na Educação Infantil. Tese de Doutorado. UERJ - Rio de Janeiro, 2016.

SIMIANO, L.; VASQUES, K. Sobre importâncias, medidas e encantamentos: o percurso constitutivo do espaço da creche em um lugar para os bebês. $34^{\text {a }}$ Reunião anual da ANPED, 2011. Disponível em: <www.anped.org.br>. Acesso em 15 mar. 2017.

TRISTÃO, F. C. D. Ser professora de bebês: um estudo de caso em uma creche conveniada. Dissertação de Mestrado. Programa de Pós-Graduação em Educação - UFSC - Florianópolis, 2004.

VIEIRA, I. C. As práticas de professoras de berçário no contexto da proposta pedagógica de uma creche municipal do interior de São Paulo: a interação e a brincadeira em destaque. Dissertação de Mestrado. UNESP - São Paulo, 2016.

VIGOTSKI, L. S. Construção do Pensamento e da Linguagem (tradução: Paulo Bezerra). São Paulo: Martins Fontes, 2009.

WINTWEHALTER, D. F.. As especificidades das práticas educativas na creche: o que as crianças expressam em suas vivências na educação infantil? Dissertação de Mestrado. UFSM - Santa Maria, 2015.

\footnotetext{
i Mestre em Educação pela UFRJ; E-mail: rachelarenari@gmail.com Rio de Janeiro/RJ; ORCID: https://orcid.org/0000-0001-9112-4014

ii Doutora em Educação pela PUC-Rio; Professora Associada do Departamento de Didática da Faculdade de Educação da UFRJ e do Programa de Pós-Graduação em Educação-PPGE-UFRJ; E-mail: corsinopat@ gmail.com Rio de Janeiro/RJ ORCID: https://orcid.org/0000-0003-4623-5318
}

Revista Interinstitucional Artes de Educar. Rio de Janeiro, V. 6, N.2- pág. 489-511 maio-agosto de 2020: "Bebês e crianças: cultura, linguagem e políticas" 